\title{
Os desafios da formação docente
}

\section{Challenges of teaching graduation}

\author{
Carlos Roberto Jamil Cury*
}

\begin{abstract}
RESUMO
Este artigo é referente à aula inaugural ministrada no Setor de Educação da Universidade Federal do Paraná no ano de 2001. Trata de reflexões acerca dos desafios da formação docente diante da realidade brasileira contemporânea a partir de explicações das transformações que ocorreram no contexto histórico educacional.
\end{abstract}

Palavras-chave: formação de professores, ensino público, educação.

\begin{abstract}
This article refers to the inaugural class taught in Education Department of Universidade Federal do Paraná in the year 2001. Here there are thoughts about challenges involving graduation of teachers, in relation to Brazilian contemporary reality, based on explanations about transformations that occurred in the historical education context.
\end{abstract}

Key-words: graduation of teachers, public education, education.

Prezados alunos, meus colegas aqui presentes! É com muita satisfação que eu venho a esta aula inaugural. Muitos de vocês talvez sejam professores e sabem muito bem que o sentido do professor só se completa com o sentido do aluno. Por isso, quando começa um novo ano letivo, nós, professores, nos sentimos em processo de realização quando vemos as classes cheias. Quando entra uma turma nova, nós nos alegramos porque é o sinal da continuidade, é sinal de que uma nova geração vai assumir mais uma fatia da sua responsabilidade com relação à sua formação e aos grandes destinos da educação brasileira. Na

* Professor aposentado da UFMG. Atualmente é docente da PUC-MG e membro da Câmara de Educação Básica do Conselho Nacional de Educação. O texto escrito mantém o estilo coloquial da fala. crjcury.bh@zaz.com.br 
Velha República, diziam que uma escola no final de semana (em geral sem aluno e também sem professor) não era uma escola, era apenas um prédio, um edifício. A presença de vocês significa nada mais nada menos, de que vocês fazem, junto conosco nos salões, nos anfiteatros, nas salas da Universidade Federal do Paraná, uma unidade formativa de ensino. Por isso, é muito honroso o convite que me foi formulado para estar aqui com vocês nesta noite, num dos momentos da recepção dos novos estudantes. Eu agradeço à direção do Setor de Educação e, de antemão, agradeço todos vocês que vieram para mais esta atividade acadêmica e solene.

Coube-me o desafio de falar sobre $O$ s desafios da formação docente. Vocês estão entrando na Universidade brasileira num momento privilegiado, o que não dizer que seja um momento só de otimismo. E um momento de travessia, é um momento de construção, é um momento de enfrentar os desafios e vocês é sangue novo de que estas instituições necessitam para dar uma resposta contemporânea aos problemas explícitos e implícitos na formação docente. Vocês são, por assim dizer, já no presente, o passaporte nessa travessia e têm um ônus. E este ônus vocês vão dividir conosco porque vocês já estão entrando na Faculdade de Educação discutindo a própria formação docente.

Quando começou a ser discutido neste país a formação de uma rede de ensino primário, com a primeira Lei de educação que houve neste país, em 1827 , estavam postos três problemas com os quais vocês vão se defrontar hoje: a) salários e carreira; b) conteúdos e disciplinas; e e) avaliação de desempenho. A Lei de 15 de outubro de 1827, uma Lei imperial, já os coloca claramente e a eles juntarse-á, anos depois, um quarto problema: as competências administrativas.

Isto quer dizer que o desafio da formação docente, isto é, daqueles que pretendem ser educadores no nível superior ou no nível básico, é enfrentar o que está ocorrendo entre nós neste momento. Ou seja, "Qual é a orientação, qual é o significado, qual é o conteúdo que nos toca como educadores numa relação pedagógica que, ao mesmo tempo, é interna à instituição e conectada com uma sociedade". E isto se dá num momento raríssimo na história do Brasil, em que por várias razões, por diferentes concepções, há uma unanimidade com relação à importância da educação escolar como um elemento fundante da cidadania e como um elemento indispensável para a presença qualificada nas relações profissionais de trabalho. Por isso, os desafios mudam de acordo com situações históricas. Um era o desafio de um país recém-independente politicamente falando, outro é o de um país que necessita dar tanto uma resposta educativa e educacional aos pesquisadores e futuros pesquisadores que continuarão decifrando o genoma, o encadeamento do genoma quando professores e professoras que deverão enfrentar o desafio de 3 milhões de brasileiros que não sabem ler e escrever. Temos 
que dar uma resposta à modernidade e também à democracia. Portanto, esse é um desafio atual que joga sobre nós uma responsabilidade muito grande em termos formativos. Mas esta responsabilidade estava posta em 1827 dentro de um outro quadro histórico, dentro de um outro quadro social. Então, para me fazer mais claro creio que seria importante trazer para vocês algumas pinceladas históricas de como é que a nação enfrentou a questão da formação docente.

A formação docente era, entre 1827 e 1834, responsabilidade da corte, isto quer dizer em termos atuais que ela seria uma responsabilidade do Governo Federal. Mas não se deve imaginar que, num país escravocrata, houvesse a possibilidade de negros nas escolas... A lei de 1827 era clara quando dizia: escola primária gratuita para os cidadãos brancos brasileiros e ainda assim só para as vilas populosas. Para as vilas não populosas, pequenas e rurais, não haveria necessidade de escola... E os professores seriam formados para a realidade polêmica e complexa desse momento.

Polêmica, porque ela é oferecida para alguns e não oferecida para outros e complexa porque o ato de ensinar, ele é em si mesmo algo polivalente com relação aos múltiplos aspectos dos estudantes. Uma coisa é a etapa inicial da escolaridade, outra coisa são vocês que estão entrando no ensino superior. Uma coisa são as crianças, outra coisa são os jovens ou os adultos. Então estamos diante de um ato complexo. $\mathrm{E}$ as nossas elites imperiais ou republicanas nunca tiveram, desde aquela época, grande interesse em propiciar educação escolar. Como justificativa diziam que éramos um país agrário, despovoado, de dimensões continentais. De outro lado, importa ressaltar uma característica dos países que sofreram a colonização ibérica. Esse tipo de colonização não atribuía maior importância à escrita e à leitura. Tiveram interesse na oralidade mas não o tiveram com relação à escrita e à leitura. Fomos países colonizados por contrareformistas em que a Contra-reforma era o prolongamento de uma concepção medieval de sociedade hierárquica. Por isso não havia muito interesse de disseminar a escrita e a leitura através da educação escolar. Mas havia a determinação do ensino primário. E qual foi a saída para isto? Sete anos depois, em 1834, a responsabilidade das escolas primárias foi atribuída às províncias (futuramente Estados na República). Só que ela foi com uma diferença muito importante. Lá, como agora, os impostos mais substantivos ficavam com a corte e os impostos mais magros ficavam com as províncias. Enquanto a corte organizava o ensino superior obviamente para uma ínfima fração das elites, delegava a educação escolar primária para as províncias. Desde 1834 até hoje, a formação docente para atuar nos anos iniciais da escolarização ficou por conta das províncias e posteriormente ficaram por conta dos Estados. Isto impõe um primeiro desafio, será que a educação dos anos iniciais da escolarização, será que a educação 
infantil é tão menos complexa do que a educação que se inicia no quinto ano do ensino fundamental e por isso para ela é suficiente um curso médio? Eis um desafio que é um desafio grave por algumas razões.

Nós temos um número enorme de pessoas em que a única maneira do governo estadual assumir a responsabilidade da escola inicial é com um curso normal médio. E por que? Vocês estão entrando numa Universidade pública, vocês estão entrando numa universidade que não cresce há mais de 25 anos e dificilmente vai crescer por conta de políticas educacionais equivocadas. Na medida em que o ensino superior se expande sob responsabilidade da instituição privada e como a atual LDB incentiva a formação de docentes em nível superior, vários governadores e secretários da educação estão lendo a Lei da educação dizendo: não é para formar professores em nível superior ? pois formemo-los em nível superior ! Consequiência: vamos fechar as escolas normais do nível médio porque os professores agora só serão formados em nível superior! E uma interpretação errada, errônea, ilegal da Lei. Mas quem é que está abrindo ensino superior? E quem é que não está abrindo ensino superior? Os Estados não estão abrindo ensino superior para a formação docente, a União não está abrindo, os municípios não podem abrir, quem abre são as instituições particulares. Conclusão: por mais que seja desejável que todos os professores façam a sua formação em nível superior não se pode agravá-los com mais este ônus e há que ter um tempo para que se possa fazer tal qualificação.

Nós temos um desafio, fazer a travessia desta estrutura que nos vem de 1834 de um curso normal médio para um curso superior universitário de formação de docentes, mas que tenha a garantia do serviço público. Ninguém põe em dúvida da necessidade, como vocês vão comprovar pelo menos durante os 4 anos de curso, que um professor do quadro universitário é um professor que tem uma soma maior de informações, que tem acesso à investigação científica, que tem acesso a uma biblioteca mais qualificada. Este é um desafio concreto, ao mesmo tempo pedagógico e político. Esse jogo dos governos estaduais não é tão novo assim, já em 1834, os interventores das províncias nomeados pelo imperador diziam: a organização da educação, a administração da educação é conosco, mas o recurso tem que vir da corte e a corte dizia: não, tem uma emenda constitucional de 1834 que joga toda a responsabilidade para vocês, nós ficamos com o ensino superior. Então nós somos herdeiros de uma situação duplamente grave: de um lado, a organização da educação brasileira nasceu de cima para baixo, do ensino superior para o ensino fundamental, e, em segundo lugar, $a$ responsabilidade formativa desses quadros que deveriam atender à educação básica e à educação fundamental fica com as províncias (posteriormente os Estados descarnados dos impostos mais significativos para dar conta do serviço público). 
Deste desafio nasce um outro: é que os anos iniciais da escolaridade e a educação infantil, por serem uma etapa de crianças, seria algo tão sério e exigente quanto lidar com meninos de 12 anos pra cima? A complexidade do ato educativo da educação infantil e do ensino fundamental seria menos complexa que a das etapas subseqüentes? De modo geral, a resposta prática foi que o professor que vai entrar nos anos iniciais da escolaridade precisa de metodologia e prática. Ele não teria necessidade de entender o quadro histórico, quadro social, quadro estrutural e teórico do que ensina. Já o professor de 5.a ano pra cima precisa de conteúdo, conteúdo de disciplinas específicas, recebendo depois umas pinceladas pedagógicas, buscando com isto fazer dele professor. Muito bem, este é o segundo desafio, há um corte estrutural na formação docente que perpassa inclusive o nível superior, mas que começa lá no curso normal médio: teoria de um lado e prática do outro. Uma dualidade, um dualismo entre teoria para um nível e prática para outro considerado menos ou mais lúdico. Então essa dualidade está posta e vocês verão isto também ao longo do curso de vocês, seja do próprio curso de vocês seja do estudo histórico/sociológico/psicológico que vocês farão desta dualidade. Vejam, são várias dualidades que se apresentam como desafio, uma dualidade é o ensino superior, o ensino médio e a segunda dualidade decorrente desta.

Ensino superior para a União e Entidades Particulares, Ensino médio para os Estados e Ensino Fundamental e Educação Infantil para os Municípios, outra dualidade seria a teoria de um lado e a prática de outro. Mas como é que esta prática se articula com o resto? Esta prática se articula com o resto para um professor menos exigente de uma forma multidisciplinar, já que ele tem que fazer muitas metodologias: metodologia de ciências, português, matemática, etc. Ele será professor polivalente, multidisciplinar. O outro não, o outro será um professor unidisciplinar como professor de uma disciplina de ensino de... Agora, nos anos iniciais, a professora pode dar conta de educação física, língua pátria, de primeiras operações matemáticas de modo prático e lúdico. Ela é multidisciplinar, precisando para isso muita metodologia, o outro de conteúdo e de apreensão de teoria no seu campo. Neste recorte, então, esse é um outro desafio que se manifesta de uma forma muito clara e preconceituosa: o ato de ensinar não seria tão complexo, bastando, para ser professor, uma camada pedagógica, uma tintura psicológica...

Esta foi uma resposta que historicamente se deu no Brasil para este segundo segmento, o segmento do $5^{\circ}$ ano em diante, através de uma equação que ficou famosa e que vocês vão estudar: o $3+1$. Eu entro para fazer Física, por exemplo, como bacharel, como físico pesquisador, como se eu fora ser um físico voltado para uma estatal ou para uma multinacional. Mas para garantir um espaço no mercado de trabalho, por que não obter mais um diploma: o de licenciado? aí este bacharel se desloca para a faculdade de educação e, durante um ano, tem as famo- 
sas matérias pedagógicas e aí se torna um licenciado. Na verdade, é um bacharel revestido de uma camada pedagógica muito frágil e que vai poder fazer os seus concursos nos sistemas de ensino para lecionar ou vai ingressar na rede privada.

Eu digo que este é um grande desafio porque recentemente a Confederação Nacional dos Trabalhadores de Educação (CNTE), juntamente com a Universidade de Brasília (UNB), fez uma pesquisa com muitos professores na totalidade dos Estados do Brasil e ela objetivava encontrar o perfil do professor. Entrevistou professores das mais diferentes áreas do conhecimento e a conclusão a que se chegou é que o motivo pelo qual os professores adoecem, adquirem doenças profissionais como calosidade nas cordas vocais, alcoolismo e outras doenças profissionais é porque eles amam ser professor. Só que eles descobriram que ser professor é ser um pequeno Deus, um criador que multiplica sem expropriar ninguém depois de vinte anos de exercício profissional. Ele tem a exata dimensão do que é ser professor e das más condições que suportam seu exercício profissional. E por terem uma aguda consciência deste vácuo entre consciência e realidade é que ele se torna uma pessoa deprimida em relação a sua própria profissão.

O exercício profissional não lhe dá as condições e mesmo assim ele se percebe limitadamente um criador. Agora o que devemos nos perguntar é: será que nós precisamos, independentemente por ora das condições precárias de exercício profissional, levar quinze ou mais anos para realmente se tornar um professor e ter a consciência plena de si como profissional no sentido de alguém que cria', que multiplica sem explorar ou privatizar? Afinal, o conhecimento e a transmissão do conhecimento têm esta virtude: são algo que o professor, ao passar para os estudantes, não só ele não perde como os alunos ganham, multiplicam e socializam sem que isso signifique uma rapinagem como pode acontecer nas relações de trabalho. Desta maneira, o desafio que hoje nós temos pela frente, profissionalmente falando, do exercício profissional se dá nas esferas dos governos municipais, dos governos estaduais, do governo federal, do governo do Distrito Federal e das unidades escolares privadas de ensino.

O desafio é: é possível formar professores desde o primeiro ano de uma licenciatura ou o professor tem que se fazer a despeito de uma formação específica? Por exemplo, vocês entraram e fizeram uma opção clara, fizeram uma opção consciente: eu quero ser Pedagogo, eu quero ser Educador.

O desafio que nós estamos vivendo hoje é isto: Como fazer com que a Universidade e as Instituições formadoras, desde o primeiro ano, possam oferecer aos pretendentes a professores uma trajetória de consciência profissional? Por que este é um desafio? Institucionalmente falando, primeiro porque nós todos temos atrás de nós aquelas dualidades, aquele dualismo entre Estado com o Normal Médio e o Ensino Superior com a União ou com Instituições Privadas, temos o dualismo da 
teoria e prática, a dualidade entre uma formação multidisciplinar reduzida e uma formação unidisciplinar bastante profunda, que conduzam a ser um bacharel e não um professor. Nada contra os bacharéis, todos tem que ter seus espaços, suas opções. Só que a nossa tradição institucional nunca teve espaço (exceto o período de 4 anos na Universidade do Distrito Federal/UDF, no Rio de Janeiro, nos anos de 1934-1937 , montada pelo Anísio Teixeira), a nossa formação docente encaminhou-se no sentido de formar, de um lado, o bacharel e, de outro lado, o professor com algumas tinturas pedagógicas: esse é o desafio institucional! Se vocês fizerem um longo estudo transversal da História da Educação brasileira do ponto de vista do profissional vocês vão constatar que a faculdade de Pedagogia ou de Educação ou outros nomes que já houve, dois grandes campos aí se instalaram. O campo do administrador saindo do Pedagogo (que posteriormente isto se desdobrou em especialista) e o Pedagogo que tinha, de um lado, uma função técnica, ser alguém entendido em estatísticas, em assuntos educacionais de um modo geral em vários campos, mas para atuar na burocracia estatal das secretarias ou nos ministérios ou então o Pedagogo que teria uma formação universitária para atuar nas escolas normais de nível médio. Exceto a experiência de Anísio Teixeira na Universidade do Distrito Federal, não se põe claramente para o Pedagogo a função do educador comprometido com a Educação Básica. Este compromisso, assumido ao longo dos anos setenta, representou uma radical consciência da importância da formação do educador e da educadora no nível superior e de preferência no nível universitário porque aqui se dá a possibilidade de continuar a conhecer e a experimentar e a descobrir novos campos através da chegada à pesquisa. Muito bem, aqui entram outros assuntos, as Universidades Públicas conseguiram resolver satisfatoriamente a questão da Pedagogia enquanto tal, mas não resolveram satisfatoriamente a questão do educador enquanto profissional de ensino nas licenciaturas. As diatribes internas são grandes: uns querem continuar com o $3+1$, outros, desqualificam as Faculdades de Educação.

Mas voltando ao campo da Pedagogia, da formação do educador há um outro desafio que é o seguinte: a área pública não cresceu, então a consciência da importância do compromisso com a educação básica ficou restrita as Universidades que são poucas. Acontece que, de 1960 pra cá, a nossa população mais do que dobrou, quantos colegas de vocês pleitearam entrar na Federal do Paraná e não entraram, quantos colegas de vocês do interior pleitearam a Federal e não entraram! Eles vão procurar as escolas disponíveis e estas isoladas, noturnas nem sempre contam com profissionais bem qualificados, mas elas são a maior fonte institucional de formação de educadores. A taxa porcentual das Universidades Públicas que formam educadores enquanto licenciados é residual. Então esse é um 
desafio político. Está posto e não adianta querer fazer, digamos assim, uma política de avestruz.

Desde os anos 1970, esse segmento privado vem crescendo na medida em que os Estados Federais se recusam a ampliar seu espaço de atuação neste nível de ensino. Pois bem, todo esse conjunto veio desaguar recentemente quando da aprovação de uma nova lei de educação, de 1996, a Lei de Diretrizes e bases, de dezembro de 1996. Esta lei está mal escrita em sua redação, contendo mesmo algumas antinomias dentro do seu próprio texto. E, na questão da formação docente, ela praticamente não avançou. Nós temos que resolver desafios com um suporte legal que não é o melhor pra dar conta deles. O Ministério da Educação, então, de acordo coma lei de 1995, alei n. 9.131/95, que criou o Conselho Nacional de Educação, enviou uma proposta no sentido de responder a estes desafios. Esta proposta, de acordo com a lei, tem que ser mandada para o Conselho Nacional de Educação e os conselheiros que tem que deliberar sobre ela.

Nos primeiros dias de aulas convencionais, vocês vão se defrontar com estes documentos e as várias versões modificadas pelo CNE e pelas sugestões advindas das audiências públicas. Esperamos que a Federal do Paraná se faça representar e faça uma leitura crítica trazendo uma contribuição significativa. São esses desafios que estão sendo discutidos por serem complexos, polêmicos e que envolvem vários aspectos da realidade do ser professor, desde o professor que quer abrir uma escola de educação infantil até o professor que queira fazer concurso para entrar na Universidade Pública, mas sobretudo os professores que querem ingressar no sistema estadual e nos sistemas municipais de ensino.

A nossa responsabilidade como instituições formadoras é muito grande. Por que é grande? Porque a Universidade é autônoma para definir os nossos rumos e os dessas diretrizes. Na Universidade, nós temos espaço de autonomia e com o aporte da pesquisa sistemática. Agora, vocês como bons alunos, serão capazes de pegar esses desafios e fazer do curso de vocês algo que os conduza a ser compromissados com a democracia social e política de que este país necessita. Vocês não devem perder um minuto da experiência que vocês trazem de vida como estudantes que cursaram desde o jardim infantil até o processo seletivo a que vocês se submeteram.

Esta nova experiência que vocês começam nesta semana, deve ser aproveitada ao máximo. Penetrem nas bibliotecas, nos laboratórios, não deixem passar um minuto do tempo que vocês têm porque este é o tempo mais precioso da formação de vocês! Nós, professores, temos o dever de responder a este compromisso com vocês. Por outro lado, um educador que saia de uma Faculdade de Educação e, sobretudo de uma Universidade Federal não tem o direito de ser um cidadão fora de seu tempo, ele tem a obrigação de ser um educador contemporâneo. 
Por isso, investir nas novas linguagens da televisão, do DVD, da internet, da informática não é lutar contra espíritos, é estar presente junto aos fatos. Ingressar, portanto, nas novas linguagens, dominar as novas linguagens, ser capaz de fazer projetos coletivos, articular-se com sistemas estaduais com sistemas municipais, com sistemas privados é fundamental. Estes 4 anos que vocês vão passar aqui devem se constituir num projeto institucional que restabeleça uma nova integração entre teoria e prática, entre conhecimento e pesquisa. Mas vai depender muito também da forma como vocês responderem a isso. Nós, professores, temos os nossos deveres, quase todos nós fizemos mestrado, doutorado e pós-doutorado, tivemos várias oportunidades de alargar nossos conhecimentos de mergulhar na investigação científica, de conhecermos um pouco mais do conteúdo. Nós também estamos desafiados por esses dualismos.

A nossa responsabilidade tem jogado com esses dois elementos cruciais: compromisso com a democracia e homens contemporâneos. Homens, no sentido genérico da palavra, homens contemporâneos. Nós temos que dar entradas em processos que não podem mais ficar restritos a uma formação muito específica, a nossa formação tem que se abrir a várias áreas do conhecimento, a estabelecer metas, a estabelecer relações de uma forma crítica, de uma forma distanciada e, ao mesmo tempo, compromissada.

Vou encerrar a minha fala dizendo o que eu entendo pelo papel das Faculdades de Educação das Universidades Públicas. A batalha quantitativa, isto é, a da predominância numérica nós já perdemos há muito tempo. Só há um caminho para recuperar esta batalha. Mas isso demandaria uma outra conversa para um outro dia, um outro horário... Nesse, deveríamos entrar de cabeça na educação à distância, já que a predominância numérica presencial já perdemos.

O que não podemos perder é o que recomendava um cientista político italiano: trata-se da hegemonia como a capacidade de dar orientação, de dar o rumo qualitativo, de ser padrão de referência e impor-se por esta virtude. E isto é o que as Universidades Públicas têm que assumir como seu compromisso.

Se este rumo for compromissado com a democracia e se esse rumo se valer da contemporaneidade das novas linguagens, das novas formas de ser presentes no mundo contemporâneo, eu tenho certeza que as Universidades Públicas estarão dando, dentro da limitação da sua disponibilidade qualitativa, um aporte extremamente significativo para os sistemas de ensino que ainda mantém cursos normais e estarão, ao mesmo tempo, possibilitando às instituições isoladas, interioranas, noturnas uma rota, um paradigma que congrega a superação do dualismo entre teoria e prática, que congrega no educador o licenciado, o especialista. $\mathrm{O}$ educador que congrega, finalmente, ao mesmo tempo, em si, o contemporâneo e o democrata. Esse é o desafio maior que vocês terão seguramente nos 8 semestres 
que terão pela frente. Ingressar nesse desafio, compreendê-lo, descarná-lo, revirálo, fazer a sua anatomia, mas sobretudo ter sempre esta perspectiva: a Universidade Pública não será aquela que vai poder dar uma resposta moderna, democrática ao conjunto das instituições formadoras de educação sob uma perspectiva qualitativa e qualificadora que até hoje não dispusemos em nossa História para o conjunto da organização da educação nacional.

Muito obrigado.

Texto recebido em 25/05/2001 